\title{
Comparing Reference Sets
}

\author{
Wolfgang Sternefeld
}

\begin{abstract}
A derivational constraint (e.g. subjacency) is a condition that must be met by each operation used in the course of generating a well-formed syntactic structure. A transderivational constraint (e.g. Fewest Steps) is a condition that must be satisfied by a derivation when compared with other derivations. In order to obey a derivational constraint, it is sufficient to look at subsequent steps of the derivation in question; for a transderivational constraint to be satisfied it is necessary to look at a certain set of other hypothetical derivations.

I will discuss several possible ways to define this set of hypothetical derivations, the so-called reference set, trying to make various options compatible with the facts. In previous work (cf. Müller \& Sternefeld (1996)), it has been demonstrated that under a certain definition of reference sets, a transderivational constraint like Fewest Steps yields wrong predictions and should be replaced by a derivational constraint, the Principle of Unambiguous Binding. In this paper I will look more closely at alternative definitions of reference sets and at the Shortest Paths Condition as another relevant transderivational concept. I will argue that this condition too yields problematic results; moreover, no correct and straightforward choice of the set of hypothetical derivations is readily available.

Granted the complex nature of transderivational constraints when compared to "ordinary" derivational constraints, these results suggest that the transderivational device should be dispensed with in the most simple (i.e. economical) theory of grammar. I will argue that the relevant data can be explained equally well by derivational constraints which substitute for economy constraints without loss of theoretical or empirical adequacy.
\end{abstract}

\section{The Economy Framework}

Within the Minimalist Program economy constraints play a central role in ruling out ungrammatical derivations. The core of the minimalist theory of economy can be formulated as a general economy condition which subsumes various more specific economy constraints proposed in the literature. This general statement of economy, given in (1) below, presupposes two supplementary definitions: First, there is a small number of more specific explications of economy which define in what ways derivations can differ; these definitions will provide us with specific measures that describe which of the different derivations are "the best ones." Second, we cannot randomly compare any derivation with any other derivation; the derivations to be compared must have something in common. So, there must be a definition of competing derivations which says in which sense the derivations to be compared must be alike.

Any set of competing derivations is called a reference set, denoted by RS. The set of specific measures will be denoted by $M$. The general economy condition stated in (1) is a constraint of Universal Grammar which says that given a certain RS, only those of its elements "survive" (i.e. will not be ruled out as ungrammatical by considerations of economy) that do best with respect to the metrical properties in $M$. The contents of the theory can thus be stated as follows: 
(1) General Economy Condition:

Given two derivations $\mathrm{D}_{1}$ and $\mathrm{D}_{2}$ in the same reference set $\mathrm{RS}, \mathrm{D}_{1}$ is preferred over $\mathrm{D}_{2}$ if and only if $\mathrm{D}_{1}$ fares better than $\mathrm{D}_{2}$ with respect to some metrical measure in $M$.

As indicated above, the set $M$ provides metrics to evaluate derivations or structures generated by the computational system. Consider, for example, the total number of FORM CHAIN operations that occur in a given derivation or the number of nodes crossed by a movement operation (to be discussed in more detail below). In combination with (1), these two measures yield the two economy constraints known as "Fewest Steps" and "Shortest Paths." For instance, if a derivation $\mathrm{D}_{1}$ contains more chains than $\mathrm{D}_{2}$ and both are in the same $R S$, then $D_{1}$ is ruled out as a violation of Fewest Steps, the relevant measure being the number of FORM CHAIN operations a derivation has. If at the same time $\mathrm{D}_{1}$ would fare better than $\mathrm{D}_{2}$ with respect to a second (different) measure in $M$, e.g. with respect to Shortest Paths, both derivations would be ruled out; cf. Chomsky (1993, p. 15), who discusses an apparent conflict between two economy constraints (Fewest Steps and Shortest Move, also called "Shortest Link" or "Minimize Chain Links") on the basis of the assumption that a violation of only one of these constraints is sufficient to rule out a derivation as ungrammatical. This is expressed more explicitly in the following reformulation of (1):

\section{Corollary:}

A derivation $\mathrm{D}_{i}$ is ungrammatical if there is a metric $m$ in $M$ and a derivation $\mathrm{D}_{j}$ in the same $\mathrm{RS}$ as $\mathrm{D}_{i}$, such that $\mathrm{D}_{j}$ fares better than $\mathrm{D}_{i}$ with respect to $m$.

Note that (2) does not prevent a given RS from containing more than one grammatical derivation. On the other hand, economy does not imply that optimal derivations are automatically grammatical; since in general each derivation is subject to additional constraints, it may happen that the most economical derivation is ruled out by an additional constraint, whereas the remaining less economical derivations satisfy all constraints except economy. In that case the RS in question fails to contain any well-formed derivation at all.

Having sketched the general framework, it remains to define and exemplify the notion of a RS, a matter to be dealt with in the next section.

\section{Defining Reference Sets}

In this section I aim to demonstrate that RSs can be defined in a number of different ways. As the empirical domain of the discussion, I have chosen superiority effects; the relevant metrics is the length of a movement path. The following three subsections illustrate three different possibilities of defining RSs, each of which has a different empirical impact on the derivation of superiority from economy. 


\subsection{Superiority and Shortest Paths}

The following quote is taken from Chomsky (1993, p. 14), where the ungrammaticality of example (9-a-ii) below is analyzed in terms of what has been called the Shortest Paths Condition:

"(9) a. (i) Whom ${ }_{1}$ did John persuade $t_{1}$ [to visit whom ${ }_{2}$ ]

(ii) $*$ Whom $_{2}$ did John persuade whom 1 [to visit $\mathrm{t}_{2}$ ]

b. $[\ldots]$

Looking at these phenomena in terms of economy considerations, it is clear that in all the 'bad' cases, some element has failed to make 'the shortest move.' In (9aii) movement of whom $_{2}$ to [Spec, CP] is longer in a natural sense (definable in terms of c-command) than movement of $w_{h o m}$ to this position ..."

Chomsky does not make the "economy considerations" explicit in a way that would allow for a complete explanation along the lines suggested. Collins (1994a), however, develops a more detailed theory. He first defines the number of nodes in a movement path as the relevant measure; following Pesetsky (1982), a path generated by move- $\alpha$ can most simply be defined as the set of nodes that dominate the trace of $\alpha$ and are c-commanded by $\alpha$. Depending on how much invisible structure we are willing to impose on the sentences in Chomsky's example (9), the path of whom $_{1}$ contains (at least) the VP headed by persuade, the $\mathrm{I}^{\prime}$ and IP whose specifier is John, and the $\mathrm{C}^{\prime}$ headed by did. It is clear, then, that the path of whom $_{2}$ must contain these nodes as a proper subset; hence, "movement of whom 2 to $[\mathrm{Spec}, \mathrm{CP}]$ is longer in a natural sense..."

Instead of counting the nodes that dominate a trace, one might as well consider the nodes that $c$-command a trace; this is the set of nodes crossed by movement. For example, if movement goes from $\alpha$ to $\beta$ as in (3), the path of $\alpha$ as defined above consists of $\mathrm{X}_{2}$ and $\mathrm{X}_{1}$, but the nodes crossed by movement are $\mathrm{Y}_{2}$ and $\mathrm{Y}_{1}$. This alternative metrics is defined in (4). It can be based on the notion of asymmetric c-command, with $\alpha$ asymmetrically c-commanding $\beta$ if and only if $\alpha$ c-commands $\beta$, but not vice versa.

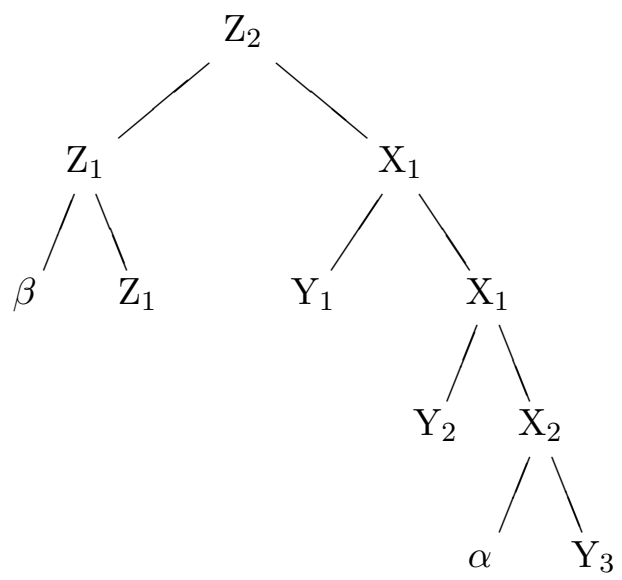

(4) Shortest Paths Metrics $\left(=M_{s p}\right)$ :

If $\alpha$ moves to $\beta, M_{s p}(\alpha \rightarrow \beta)$ is the number of categories $\mathrm{Y}$ such that 
a. Y asymmetrically c-commands $\alpha$ and

b. $\beta$ (asymmetrically) c-commands Y.

According to (4), it is did, John, and persuade themselves that form the path of whom in (9-a-i). Although the two ways of defining the length of a movement path yield the same empirical results, I will use (4) as the basis for further modifications below.

Having defined the length of a single movement, it remains to define the length of an entire derivation. Intuitively, this is the sum of the lengths of the movement operations or links it contains. To be precise, let me quote Collins' definition of "nodes traversed" (from Collins (1994a, p. 56)):

(5) Nodes traversed:

Let $\mathrm{D}$ be a derivation, and $\left\{\mathrm{L}_{i}\right\}_{\mathrm{D}}$ its links. Let $\pi_{i}$ be the path associated with $\mathrm{L}_{i}$ and $\mathrm{N}_{i}$ be the cardinality of $\pi_{i}$, i.e. $\mathrm{N}_{i}=\mathrm{M}_{s p}\left(\pi_{i}\right)$. The number of nodes traversed is defined as follows: $\mathrm{M}_{s p}(\mathrm{D})=$ the sum of $\mathrm{N}_{i}$ for $\mathrm{L}_{i}$ in $\left\{\mathrm{L}_{i}\right\}_{\mathrm{D}}$.

(6) Length of a derivation:

$\mathrm{D}_{2}$ is longer than $\mathrm{D}_{1}$ if and only if $\mathrm{D}_{2}$ traverses more nodes than $\mathrm{D}_{1}$, i.e. if and only if $\mathrm{M}_{s p}\left(\mathrm{D}_{1}\right)<\mathrm{M}_{s p}\left(\mathrm{D}_{2}\right)$.

(7) Shortest Paths Condition:

If two derivations $D_{1}$ and $D_{2}$ are in the same $R S$ and $D_{2}$ is longer than $D_{1}$, then $\mathrm{D}_{1}$ is to be preferred over $\mathrm{D}_{2}$.

It is clear that (7) is implied by the general constraint (1), with the relevant metrics being defined as $\mathrm{M}_{s p}(\mathrm{D})$. It only remains to explain the notion of a RS, which is defined by Chomsky (1995, p. 393) as in (8):

Reference Set (1):

Two convergent derivations are in the same RS if and only if they have the same numeration.

A numeration is understood as a complete list of occurrences of the lexical items used by the computational system in the course of a derivation. Accordingly, all superiority violations should result from a wh-phrase having made a longer move than another whphrase in an alternative derivation with the same numeration, i.e. the same lexical material.

Note that for this analysis to work properly, it seems necessary to assume that two numerations count as identical even if two of their elements differ in the strength of their features. This simply follows from the assumption that the overtly moved item $w_{h o m}$ in (9-a-i) has a strong feature (in the sense of the minimalist theory), whereas the wh-phrase whom $_{2}$ which remains in situ must have a weak feature (for otherwise both whphrases would have to move). In contrast, (9-a-ii) must exhibit the converse distribution of features. Accordingly, if we want to compare two derivations which differ with respect to whether or not an item moves, it seems best to disregard the strength of the features that trigger movement.

However, there is a potential problem here, arising from optional movement. As a representative example, consider wh-movement in French, illustrated in (9): 
(9) Optional movement in French:

a. $\mathrm{Tu}$ as vu qui ?

You have seen whom

b. Qui $_{j} \quad \mathrm{as}_{k}$-tu $\mathrm{t}_{k}$ vu $\mathrm{t}_{j}$ ?

Whom have-you seen

Given the feature account of movement and the wh-criterion, optionality of wh-movement will arise if the feature of the wh-phrase can choose either a strong or a weak value. But as soon as the difference between weak and strong features is ignored when defining RSs, it seems that the variant without movement will incorrectly block the option of movement. We therefore have to assume that of the two features relevant for one single movement (namely the feature of the wh-phrase that becomes checked after movement and the corresponding feature that does the checking), it is the feature of the moved item that is irrelevant for RS. Nonetheless, strong and weak features of heads - in so far as they check movement of other elements - will still matter in the definition of RSs so that the two derivations, one with and the other without movement, can be put into different RSs.

Another example of sloppiness in identity conditions for RSs is provided by the following paradigmatic case for superiority; since movement of what is longer than that of who, the contrast in (10) should be explained straightforwardly by economy:

Subject/object superiority:

a. Who bought what?

b. *What did who buy?

However, abstracting away from word order (which is what numerations do) will not leave us with the same morpho-syntactic material, as would be necessary for having the same numeration. We conclude that for the two sentences to be in the same RS, identity of numeration cannot be understood too literally, which forces us to ignore different realizations of tense, "inserted elements," or other items that do not truly constitute lexical categories in the narrow sense of the term (cf. Emonds (1985)).

\subsection{Anti-Superiority Effects: A Revised Definition of Reference Sets}

Despite its original appeal, the economy account faces further problems that call for more radical modifications. It has been noticed by Huang (1982, p. 576), Lasnik \& Saito (1992, p. 120), and others that the grammatical sentence (12-a) refutes the superiority condition as stated in Chomsky (1973, p. 246):

The Superiority Condition:

a. No rule can involve $\mathrm{X}, \mathrm{Y}$ in the structure

...X.....Z...WYV...]...

where the rule applies ambiguously to $\mathrm{Z}$ and $\mathrm{Y}$, and $\mathrm{Z}$ is superior to $\mathrm{Y}$.

b. The category A is 'superior' to the category B if every major category dominating A dominates $\mathrm{B}$ as well but not conversely. 
The counterexample:

a. Who wonders what ${ }_{1}$ who $_{2}$ bought $t_{1}$ ?

(S-structure)

b. ([e] who wonders) $[\mathrm{e}] \mathrm{who}_{2}$ bought what ${ }_{1}$

(D-structure)

Movement of what $_{1}$ into the lower SpecC position [e] of (12-b) violates superiority, since there is another wh-phrase $w_{h} o_{2}$ that could move into [e] and is closer to [e] than what is. Yet (12-a) does have a grammatical reading, namely the one in which $w_{h} o_{2}$ has matrix scope. Therefore, (11) is too strong as it stands.

This line of reasoning also carries over to the present explanation of superiority in terms of Shortest Paths. Thus, compare the following two sentences:

Anti-superiority:

a. Who wonders what ${ }_{1}$ who $_{2}$ bought $t_{1}$ ?

b. Who wonders who $_{2} t_{2}$ bought what ${ }_{1}$ ?

The problem here is that the derivation in (13-b) blocks (13-a) on account of the same considerations that would (legitimately) apply to (10); having identical numerations, the two sentences in (13) are in the same RS, but again, movement of $w h o_{2}$ in (13-b) is shorter than movement of what $t_{1}$ in (13-a), and therefore (13-a) is blocked by economy. However, this blocking effect, albeit desirable as far as (10) and Chomsky's examples (9) are concerned, is unwarranted for (13-a).

Looking at the examples more closely, it seems that the trouble arises from the ability of one derivation to block another derivation without them having the same semantic interpretation. Hence, the above data suggest that an additional factor is to be taken into account, namely LF. And as far as LF is concerned, it appears that already Baker's (1970) ambiguity illustrated in (14) lends independent support to a revision of the relevant economy constraint:

LF-movement and Shortest Paths:

who knows where we bought what

$\uparrow$ longer, but grammatical

Given that the scope ambiguity of what is accounted for by LF movement into either the matrix SpecC of who or the embedded SpecC of where, the shorter move should not block the longer one; otherwise, no scope ambiguity could arise. Hence, under classical assumptions about LF movement, comparison of LFs should make the correct prediction, because it implies that the two sentences belong to different RSs. In the light of similar evidence, Kitahara proposed the following reformulation of the relevant economy condition:

Shortest Paths (cf. Kitahara (1993, p. 109)):

Given two convergent derivations $\mathrm{D}_{1}$ and $\mathrm{D}_{2}$ with the same LF output, both minimal and containing the same number of steps, $\mathrm{D}_{1}$ blocks $\mathrm{D}_{2}$ if $\mathrm{D}_{1}$ 's chains are shorter. 
In Kitahara's formulation the Shortest Paths requirement is operative only if the derivations already satisfy other economy constraints, i.e. contain the same number of steps and are 'minimal' (a condition not discussed here; note that (15) is identical with the condition in Chomsky (1993, p. 34), except for the phrase "with the same LF output" added by Kitahara). This particular arrangement of conditions contrasts with the more general theory pursued here which presupposes that the economy conditions are independent from one another. I find no reason to depart from this practice; hence, I simplify and reformulate $(15)$ as (16):

Shortest Paths (revised):

Given two convergent derivations $D_{1}$ and $D_{2}$ with the same LF, $D_{1}$ blocks $D_{2}$ if $\mathrm{D}_{1}$ 's chains are shorter.

Accordingly, the appropriate notion of RS, which is required in order to derive (16) from the general economy condition (1), is the following:

Reference Set (2):

Two convergent derivations are in the same RS if and only if they have the same numeration and the same LF.

Thus, it would seem that the counterexamples to Chomsky's (1973) superiority condition no longer pose a problem, and indeed, the required distinction that makes (13-a) and (13-b) elements of different RSs can easily be derived from the different scopal positions that result from LF-movement of the in situ wh-phrases.

However, alluding to LF movement creates a number of additional problems. First, recall that in all true superiority cases the overtly moved item "substitutes" in SpecC (i.e. generates SpecC), whereas the covertly moved phrase is adjoined to SpecC. Following the convention of Müller \& Sternefeld (1994, p. 472ff), covert adjunction of wh-phrases in English goes to the same position as overt adjunction in certain Slavic languages, hence to the right of SpecC (rather than to its left, as seems to be common practice; cf. Kayne (1994)). Thus, the two competing LFs for Chomsky's examples have the specifiers shown in (18):

$$
\begin{aligned}
& \text { Structure of specifiers: } \\
& \text { a. }\left[\begin{array}{lll}
\mathrm{CP} & \left.\left[\left[\mathrm{whom}_{1}\right] \mathrm{whom}_{2}\right] \ldots\right] \\
\text { b. } & {\left[\mathrm{CP}\left[\left[\mathrm{whom}_{2}\right] \mathrm{whom}_{1}\right] \ldots\right]}
\end{array}\right.
\end{aligned}
$$

It is clear, then, that these structures are, strictly speaking, non-identical although they should belong to the same RS. We must assume, therefore, that by definition the two SpecC positions count as identical with respect to sameness of LF.

A more severe problem arises from taking into consideration the length of LF paths. By way of illustration, consider Chomsky's examples, repeated here as (19) for convenience. Making minimal but traditional assumptions with respect to the underlying structure, we see that $w_{h o m}$ in (19-a) crosses two nodes (John and did), and whom 2 crosses six positions at LF (to, PRO, t $t_{1}$, persuade, John, and did), which makes a total of eight nodes. 
Shortest Paths metrics (S-structure $+L F)$ :

a. Whom ${ }_{1}$ did John persuade $\mathrm{t}_{1}\left[\mathrm{PRO}\right.$ to visit whom $\left._{2}\right]$

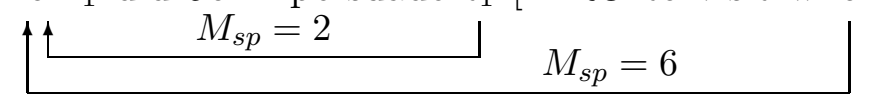

b. ${ }^{*}$ Whom $_{2}$ did John persuade whom $_{1}\left[\right.$ PRO to visit $\left.t_{2}\right]$

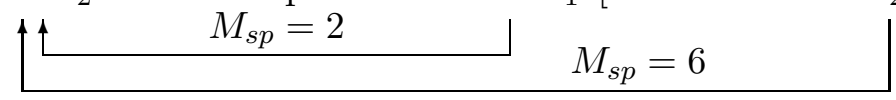

Conversely, overt movement in (19-b) crosses six positions in our "minimal" representation (words and empty categories), and covert movement crosses only two, again a total of eight positions. Hence, LF movement would level out the distinctions needed for explaining superiority.

Now, according to Reinhart (1992), Chomsky (1993), Reinhart (1994), and others, the traditional assumption that movement of wh-in-situ phrases is compulsory at the level of LF has been challenged by semantic considerations. According to Reinhart, wh-words are not interpreted as operators but rather function as bound variables. The relevant binder of these variables is an abstract operator (located in $\mathrm{SpecC}$ or adjoined to $\mathrm{CP}$ ) which roughly corresponds to the abstract Q-morpheme postulated by Baker (1970). This abstract operator simultaneously binds all wh-phrases which have, according to traditional terminology, the same "scope" as the abstract operator. There is no LF-movement of whphrases.

Following this line of reasoning allows us to get rid of the disturbing effect of LF movement in the calculation of the length of movement. On the other hand, lack of LFmovement does not in and of itself solve the problem. Defining RSs by LF-identity would imply that the two derivations in (19) cannot compete. Since they have different surface structures, they also have different LFs (by lack of LF-movement); hence, we are deprived of any means to explain superiority.

\subsection{LF vs. Meaning: A Third Definition of Reference Sets}

As a reaction to this problem, Kitahara (1993, p. 115) proposes that economy considerations should take into account semantic interpretation rather than LF as such. Since the LFs in (19) coincide with their S-structures (by lack of LF movement), they are different, but

"as far as LF interpretation is concerned, these two LF representations [corresponding to (19)] are identical. Taking 'LF output' [...] to mean 'LF interpretation', I assume that [...cases like (19-a) and (19-b)] yield the same LF output precisely because they have the same LF interpretation [...]"

In other words, what he proposes in terms of "LF output" is (20):

(20) Reference Set (3):

Two convergent derivations are in the same RS if and only if they have the same numeration and the same semantic interpretation. 
It now follows that what distinguishes the grammatical anti-superiority data from the true superiority effects is that the two derivations to be considered in the real cases of superiority are in the same RS, whereas the grammatical cases, repeated as (21) for convenience, differ in semantic interpretation, and hence cannot compete with respect to economy considerations.

Anti-superiority effect (=(13)):

a. Who wonders what who $_{2}$ bought $\mathrm{t}_{1}$ ?

b. Who wonders who $_{2} \mathrm{t}_{2}$ bought what $_{1}$ ?

\subsection{Problems and Prospects}

Summarizing so far, I illustrated three different definitions for RSs: One is Chomsky's original proposal, which led to difficulties with the Shortest Paths Condition when applied to anti-superiority data. These in turn suggested a new definition of RSs in terms of LF identity, also compatible with most of the arguments in Epstein (1992) or Müller \& Sternefeld (1996). As argued above, this redefinition still did not work for the case under discussion, so I (provisionally) adopted Kitahara's proposal to define RSs in terms of identity of meaning; this version is also defended in Fox (1994), to which I return below.

Using Kitahara's definition implies that one has to subscribe to a crucial assumption not shared by everyone working in the generative framework, namely, that there is no LF movement of wh-phrases. Moreover, the very idea of defining RSs in terms of meaning is vulnerable to conceptual objections. Most importantly, a semantic concept has been incorporated into an otherwise purely syntactic theory; this move clearly runs against the so-called autonomy of syntax. Granted that the data in question could alternatively be accounted for in purely syntactic terms (albeit not necessarily within an economy approach; cf. Epstein (1993)), invoking identity of semantic interpretation is a challenge to Occam's razor.

Furthermore, the global character of economy constraints becomes more and more unconstrained. Previously, the globality of the theory consisted in the fact that one could evaluate derivations only after it became clear that they converged, i.e. when they were terminated at LF. This is no longer sufficient in a theory that extends to meaning. Here we can compare derivations only after having computed a semantic interpretation. As regards interpretation, however, it is not totally clear precisely how "LF-output" or "meaning" should be understood; cf. e.g. Fox (1994) for some discussion of controversial points of view.

In the next section I will show that there is also an empirical problem with referring to meaning. In any case, it seems necessary to discuss more data and more consequences of the Shortest Paths Condition. This will be done in the next three sections.

\section{Scrambling in German and Korean}

In order to be precise about meaning, I assume meaning to be understood in terms of truth conditions. Accordingly, two sentences differ in meaning if and only if they have 
different truth conditions. An argument against defining RSs in terms of identity of lexical choice and identity of meaning could then be based on two grammatical derivations that have identical truth conditions but differ with respect to the Shortest Paths metrics. Such sentences can easily be found in languages that exhibit more word order variation than English.

Let us first look at German main clauses which exhibit verb second order as a result of topicalization of any maximal projection (which would remain in situ in subordinate clauses). Since the topicalized item can be reconstructed, topicalization does not influence truth conditions. Now, since topicalization of an object is longer than topicalization of a subject, we must ensure that these derivations are in two different RSs. This in turn is possible only if they have different numerations, which will be the case if there is a certain top-feature on the topicalized item that enters into numerations. Recall, however, that we decided above that the feature of a moved (wh-)phrase should be irrelevant for numerations. This assumption should now be called into question, since it looks as if we were driven into an arbitrary decision as to which features count for calculating numerations and which don't.

Let us therefore revise our assumptions about wh-features, assuming now that these features are weak in languages that have fronting of at most one wh-phrase, and that they are strong in languages that exhibit overt fronting of all wh-phrases. In English, then, wh-movement is triggered by the strong head of a CP, as before, but the weak feature of the wh-phrases will still count (insignificantly) for numeration. Since features of moved items now play a role again, we can account for the possibility of free topicalization of any maximal projection.

Our next step is to look at the interaction between topicalization and scrambling. Whereas topicalization is usually analyzed as movement into SpecC (followed by movement of the verb into C; cf. Thiersch (1978)), scrambling is analyzed as adjunction to IP or VP (or any functional projection between them). A standard proof for the existence of scrambling (and against analyzing a scrambled object as being base-generated in its surface position) is based on the following two assumptions:

\section{Basic tenets:}

a. Exactly one maximal projection per clause can be topicalized.

b. A transitive verb alone does not constitute a maximal projection.

Now, the possibility of fronting a transitive verb without its object, as exemplified in (23), is regarded as evidence that topicalization must be preceded by movement (i.e. scrambling) of the object out of its VP (cf. Thiersch (1982), Besten \& Webelhuth (1990)):

$$
\begin{aligned}
& \text { Remnant topicalization (1): } \\
& {\left[\mathrm{vP}_{1} \mathrm{Zu} \text { küssen }\right]_{2} \text { hat gestern keiner }[\text { NP die Antje }]_{1} t_{2} \text { versucht. }} \\
& \text { to kiss has yesterday no-one ART Antje } e_{\text {acc }} \text { tried }
\end{aligned}
$$

I assume that the infinitival marker $z u$ in (23) has been incorporated into the verb and that scrambling in (23) is (string-vacuous) adjunction to the VP whose lower segment has undergone topicalization. Now, as pointed out by Müller (1995, p. 89), adjunction of the NP to IP as shown in (24) would be as grammatical as (23). 
Remnant topicalization (2):

a. $\quad{ }_{\mathrm{vP}} \mathrm{t}_{1} \mathrm{Zu}$ küssen $]_{2}$ hat $\left[_{\mathrm{NP}} \text { die Antje }\right]_{1}$ gestern keiner $\mathrm{t}_{2}$ versucht. to kiss has ART Antje acc yesterday no-one tried

b. $\quad\left[\mathrm{vP}_{1} \mathrm{Zu} \text { küssen }\right]_{2}$ hat gestern $[\mathrm{NP} \text { die Antje }]_{1}$ keiner $\mathrm{t}_{2}$ versucht. to kiss has yesterday ART Antje acc no-one tried

Paradoxically, the perhaps most natural, unmarked, or "coherent" variant is (24-a) where the object has moved as close to the topicalized VP as possible. But, as Müller observes, this is also the variant that calls for the longest path. Since there is no detectable difference in numeration or meaning, this derivation is (incorrectly) blocked by the other derivations.

Basically the same holds if we reverse the positions of the subject and the adverb:

Remnant topicalization (3):

a. Zu küssen hat die Antje keiner gestern versucht.

b. Zu küssen hat keiner gestern die Antje versucht.

c. Zu küssen hat keiner die Antje gestern versucht.

Here again, the more acceptable variants seem to be the ones with the longer paths.

Remnant topicalization in German has been used by Müller (1995) as an argument against defining RS in terms of numeration alone; here we have seen that the same argument carries over to identity of meaning. One might object, however, that there is an easy way to overcome the problem. Since scrambling in German is local, one might try to revise the Shortest Paths metrics by introducing an appropriate notion of equidistance along the lines proposed in Chomsky (1993). The effect of such a move should be that the paths of scrambling are of equal length. This solution, however, does not work for languages with long distance scrambling, like Korean. The following data (courtesy of Shin-Sook, p.c.) show that the landing site of scrambling can be in different finite clauses. Consequently, relaxing locality to permit Korean scrambling - even on a parametric basis - would empty locality of any content whatsoever, thus ruling out any appeal to equidistance:

Long distance scrambling in Korean:

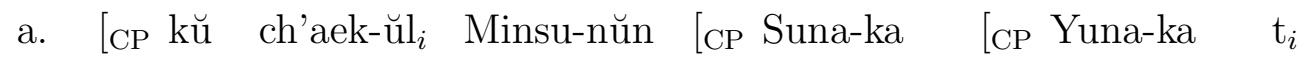
that book-ACC Minsu-TOP Suna-NOM Yuna-NOM

ilk-ŏss-ta-ko] saengkakha-n-ta-ko] malha-ŏss-ta].

read-PAST-DECL-C think-PRES-DECL-C say-PAST-DECL

'That $\operatorname{book}_{i}$, Minsu said that Suna thinks that Yuna read $t_{i}$.'

b. $\quad\left[\right.$ CP Minsu-nŭn $\left[\begin{array}{llll}\text { CP ku } & \text { ch'aek-ŭl } l_{i} & \text { Suna-ka }\end{array}{ }_{\text {CP }}\right.$ Yuna-ka $t_{i}$ Minsu-TOP that book-ACC Suna-NOM Yuna-NOM

ilk-ŏss-ta-ko] saengkakha-n-ta-ko] malha-ŏss-ta]. read-PAST-DECL-C think-PRES-DECL-C say-PAST-DECL

'Minsu said that that book $_{i}$, Suna thinks Yuna read $t_{i}$ ''

Since movement in (26-a) is longer than in (26-b), the Shortest Paths Condition makes 
wrong predictions with respect to sameness of numeration. Moreover, sameness of "LFoutput" also leaves us with a problem, since all variants, albeit stylistically not exactly equivalent, turn out to have the same truth conditions. Granted that identity of meaning would put both sentences into the same RS, and given that identity of numeration alone makes the wrong prediction, it seems that we are forced to define RSs in terms of LF identity (which in the above examples happens to coincide with surface order, i.e. S-structure).

Such a return to LF-identity, however, would call for a different explanation of the superiority effects. Recall that if we adopt a theory without LF movement of wh-phrases, LFs coincide with S-structure, but for superiority effects it is crucial that the competing sentences differ at S-structure; hence, a return to LF identity precludes any explanation of superiority. If, in contrast, we do assume LF-movement, we get the wrong result with respect to Shortest Paths, because LF movement seems to even out the overall lengths of paths in competing derivations.

Now, a conceivable approach to the problem would be to manipulate the notion of distance that enters into Shortest Path Metrics, so that LF-raising turns out to be shorter than overt raising. Suppose we calculate the length of a path by counting not the number of nodes but rather the number of chains crossed by move- $\alpha$ :

Shortest Paths Metrics (revised):

If $\alpha$ moves to $\beta, M_{s p}(\alpha \rightarrow \beta)$ is the number of chains $\mathrm{Y}$ such that for each element $\mathrm{Y}_{i}$ of $\mathrm{Y}$ :

a. $\quad \mathrm{Y}_{i}$ asymmetrically c-commands $\alpha$ and

b. $\beta$ (asymmetrically) c-commands $\mathrm{Y}_{i}$.

Looking back at Chomsky's example (19) again, we get the correct result. This is illustrated in (28):

(28) Chomsky's superiority example:

a. Whom ${ }_{1}$ did John persuade $\mathrm{t}_{1}$ [ PRO to visit whom ${ }_{2}$ ]

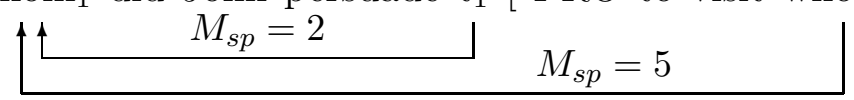

b. ${ }^{*}$ Whom $_{2}$ did John persuade whom $_{1}\left[\right.$ PRO to visit $t_{2}$ ]

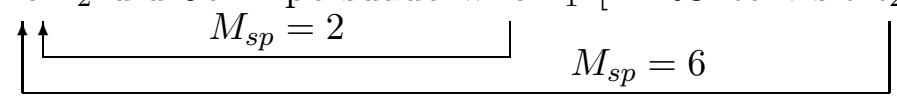

whom $_{1}$ in (28-a) again crosses two positions, but subsequent LF movement of whom 2 crosses only five positions, since the chain of $w h o m_{1}$ is not crossed. This makes a total of seven chains. In (28-b), however, overt movement crosses one chain more than covert movement because it crosses the one-element chain whom ${ }_{1}$ as well.

As a result, then, it seems that we can get the correct result with identity of LF, but only if we assume that there is LF movement and revise the definition of the Shortest Paths Metrics. 


\section{Cyclicity and Shortest Paths}

Let us now look at yet another of Chomsky's examples that allegedly is explained by Shortest Paths. In this case, Shortest Paths does not deal with superiority, but rather applies to data that were previously explained by the strict cycle condition. Although Chomsky suggests that we can dispense with the cycle, it will be shown that there are still some phenomena that follow from the cycle but cannot be explained by Shortest Paths.

The strict cycle effect which is captured by Shortest Paths is illustrated by the derivation shown in (29):

*Who was $\left[\alpha\right.$ a picture of $\left.t_{w h}\right]$ taken $t_{\alpha}$ by Bill?

"This is a CED violation if passive precedes wh-movement, but it is derivable with no violation (incorrectly) if the operations apply in countercyclic order, with passive following wh-movement. In this case, natural economy conditions might make the relevant distinction between the competing derivations. Passive is the same in both; wh-movement is 'longer' in the wrong one in an obvious sense, object being more 'remote' from [SPEC, CP] than subject in terms of number of XPs crossed. The distinction should be captured by a proper theory of economy of derivation ..." (Chomsky (1995, p. 412))

Note that Chomsky's explanation works with any of the definitions for RSs we contemplated so far, even with one based on S-structure identity. It seems, then, that the derivation of (29) from the Shortest Paths Condition is unproblematic as such and makes the cycle - a derivational constraint - superfluous as an independent principle of grammar.

However, if we look at other strict cycle effects, it turns out that these cannot be captured by Shortest Paths. Let us, for example, discuss the possible derivational histories of $(30)$ :

* How $_{i}$ do you wonder what to fix $\mathrm{t}_{i}$ ?

Basically, two derivations need to be considered, one cyclic and one acyclic. Let us begin with the acyclic derivation sketched in (31). We start with the inner cycle in (31-a) and (31-b), and then go to the second cycle in (31-c) and (31-d). The last step in (31-e) is the movement that violates the strict cycle:

Acyclic derivation:

a. PRO to fix what how

b. how PRO to fix what

c. do you wonder how PRO to fix what

d. how do you wonder PRO to fix what

e. how do you wonder what PRO to fix

Note that this derivation does not violate any locality conditions. This contrasts with the cyclic derivation given in (32). The last step of the derivation violates the ECP since the adjunct has to move across a barrier for antecedent government: 
Cyclic derivation:
a. PRO to fix what how
b. what PRO to fix how
c. do you wonder what PRO to fix how
d. how do you wonder what PRO to fix

But now observe that by the revised Shortest Paths Metric (27), the Shortest Paths Condition would exclude the cyclic derivation by preferring the acyclic one. This follows from counting the chains crossed during the derivation, as indicated by "CC" = "chains crossed" in the brackets below:

(33) Acyclic derivation:

a. [IP PRO to [VP [VP fix what] how ]]

$\left(M_{s p}=0\right)$

b. [CP how [IP PRO to fix what $t]]$

$(\mathrm{CC}=$ to and $P R O)$

c. do you wonder [ $\mathrm{CP}$ how PRO to fix what $\mathrm{t}$ ]

$\left(M_{s p}=2\right)$

d. how do you wonder $[\mathrm{CP} P R O$ to fix what $\mathrm{t}] \quad(\mathrm{CC}=d o$, you, and wonder;

$\left.M_{s p}=5\right)$

e. how do you wonder [CP what PRO to fix t t ] $\left(\mathrm{CC}=P R O\right.$ and $\left.t o ; M_{s p}=7\right)$

Cyclic derivation:

a. PRO to fix what how

$\left(M_{s p}=0\right)$

b. what PRO to fix how

c. do you wonder what PRO to fix how

$(\mathrm{CC}=P R O$, to, how $)$

d. how do you wonder what PRO to fix

$\left(M_{s p}=3\right)$

$(\mathrm{CC}=$ do, you, wonder, PRO, to;

$$
\left.M_{s p}=8\right)
$$

Acyclic movement has shorter paths because movement of what in the cyclic derivation has to cross one more position, namely how, which moves first in the acyclic derivation and is not crossed by later movement of what.

What can we conclude from the above example? On the face of it, it seems that the revised mechanism chosen to account for superiority is based on an accidental side effect: the fact that it prefers acyclic derivations over cyclic ones might indicate that it is on the wrong track.

On the other hand, if we were to return to the original idea of measuring the length of a path in terms of its nodes rather than chains, it turns out that the paths of both derivations have the same length, so that the Shortest Paths Condition is unable to distinguish between the cyclical and the acyclical derivation. Consequently, there is reason to believe that the cycle is still needed as an independent principle of grammar. But if this conclusion is correct, the acyclic derivation simply cannot be generated and therefore cannot compete with the cyclic one. This in turn implies, however, that the validity of our revision of the Shortest Paths Metrics is not yet impeached: our only conclusion at this point of the investigation is that data like (29) cannot be used to motivate the Shortest Paths Condition.

As regards the cycle under minimalist assumptions, its existence as an independent principle of grammar has been challenged by Chomsky's (1993) extension condition: one 
might argue that the last step of the acyclic derivation (33-e) has to "recreate" the inner SpecC node in a way that is inconsistent with the requirement that movement always extends a tree. Given this condition (the ExC), there is still another way to derive the ungrammaticality of (29): early extraction of the wh-phrase before the subject has been moved clearly violates the ExC. We thus have the following overlap of conditions:

a. Shortest Paths overlaps with the cycle, but neither implies the other.

b. Shortest Paths overlaps with the ExC, but neither implies the other.

c. The cycle implies the ExC.

(35-c) says that the ExC and the cycle overlap; in fact, as far as S-structure movement is concerned, their empirical predictions are exactly the same. However, since at the time of SPELL OUT (or S-structure) the structure is already (almost) complete, the ExC cannot hold for LF movement. Accordingly, since the ExC, as opposed to the cycle condition, cannot determine the sequence of rules at LF, there might still be evidence that the cycle is stronger than the ExC. In order to verify this hypothesis, let us look at cycle effects of quantifier raising and the traditional mechanism of wh-movement at LF.

As far as the latter is concerned, Müller (1995) has pointed out that there are cycle effects at the level of LF in languages like Chinese or Korean that do not have overt wh-movement (cf. Huang (1982, p. 525ff), Lasnik \& Saito (1984, p. 243), Lasnik \& Saito (1992, p. 30ff), Koster (1987, p. 216ff)); as for quantifier raising, the next section contains an example of a derivation that crucially involves cyclical QR. Anticipating these results, I conclude that the cycle is indeed an independent principle of a derivational theory.

To summarize, we have shown that Shortest Paths cannot capture all strict cycle effects and that therefore the cycle is still needed as a principle of grammar. Moreover, we have seen that superiority effects suggest a definition of RS in terms of meaning. On the other hand, there is conflicting evidence from scrambling in German and Korean that favors a definition in terms of identity of LF. The conflict can, however, be resolved by assuming LF-identity to be the relevant criterion for defining RSs, and by revising the metrics for Shortest Paths. As a result, the only consistent theory that can handle all the data discussed so far is the one that adopts the cycle, LF-movement, LF-identity, and counting chains as a metrics for Shortest Paths.

\section{Quantifier Raising}

The above result has been challenged by considerations concerning quantifier raising. Perhaps the most compelling argument in favor of identity of meaning and against the above attempt to define RSs in terms of identity of LF is due to Fox (1994), who shows that quantifier raising (QR) is ruled out by transderivational economy if and only if it is superfluous with respect to truth conditions, i.e. if it yields no difference in semantic interpretation when compared to an alternative derivation without QR.

At first sight this restriction seems empirically vacuous: if there is no difference in meaning, there is no way to tell whether or not LF-movement has applied. However, Fox shows that in VP-ellipsis constructions, the restriction interacts with a parallelism constraint in an empirically detectable manner. The parallelism constraint dictates that 
if QR applies in a clause containing a VP-deletion, it must also apply in the clause containing the antecedent VP; conversely, if QR does not apply in the VP-deletion clause, it may not apply in the antecedent clause (cf. (36-a)). The central empirical observation is that QR is blocked in an antecedent clause (even though it would not be meaning invariant there) if it is meaning invariant in the clause containing the VP-deletion (cf. $(36-b))$.

(36) a. Some boy loves every teacher, and some girl does too.

b. Some boy loves every teacher, and Mary does too.

Whereas (36-a) is ambiguous, (36-b) is not. The account of the ambiguity of (36-a) goes as follows. Suppose the representation of (36-a) before SPELL OUT and VP-deletion is (37-a), where small caps indicate the parts that are parallel:

\footnotetext{
a. Some boy [vp LOVES EVERY TEACHER ] and some girl [vp LOVES EVERY TEACHER ]

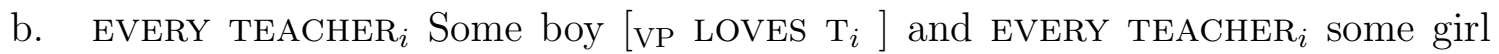
[VP LOVES $\mathrm{T}_{i}$ ]
}

(37-b) is generated by first QRing every teacher in the second conjunct and then doing the same in the first conjunct. The order of rule application is dictated by cyclicity, given the structure of coordination in (38):

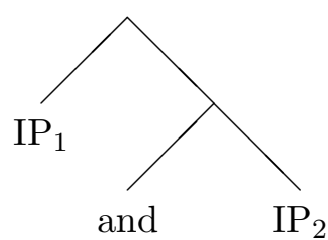

Turning next to (36-b), it is clear that QR in the second conjunct would be meaning invariant, since a proper name cannot receive a scope dependent interpretation. Accordingly, QR here is ruled out by Fewest Steps: since the second conjunct is generated first, lack of QR there will block QR in the first conjunct, and the reading represented by (39) cannot be derived:

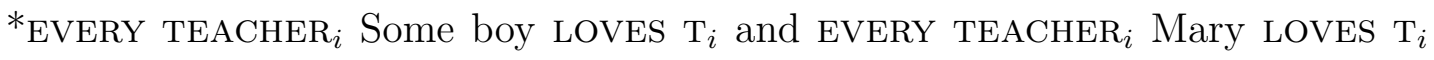

At this point, two things should be noted. First, for this explanation to work it is crucial that it is the second conjunct that blocks QR in the first conjunct, rather than the other way around. This follows only from cyclicity, but not from any other known principle of grammar. Second, Fox's transderivational account differs in nature from previous cases since it requires that the legitimacy of $\mathrm{QR}$ be checked locally, i.e. in a cyclic manner. Therefore, Fox's theory does not lend support to a theory of global economy. Rather, economy is encoded as a restriction on a local domain (or a single rule application), hence derivationally.

If something like this is correct, it seems that we are again in a predicament. As far as English is concerned, identity of meaning seems to make the correct predictions. However, 
phenomena from other languages seem to favor an alternative definition in terms of LF. In the previous sections we have been developing a theory in which all data observed are accounted for by one definition. A closer look at the facts, however, will reveal that such a strategy might overshoot the mark in not recognizing language-specific differences. In particular, the data from German and Korean which favor a definition in terms of LF (rather than meaning), have no parallel in English, and conversely, there is no VP-deletion in German and Korean as there is in English; hence, Fox's argument in favor of identity of meaning does not invalidate our previous account of the German data. One might then propose that the best way to deal with the facts is to allow for a certain amount of parametric variation in the definition of RSs.

\section{Reference Sets as Parameters?}

Suppose now that LF-identity is indeed the correct choice for languages like German and Korean but that English uses the rival definition of RS based on identity of interpretation.

This possibility of parametrization opens up a number of further possibilities and seems to be called for on independent grounds. Recall that our first theory based on LF-identity did not allow us to derive superiority. And indeed, it has been claimed in the literature (cf. e.g. Haider (1983) as an early reference) that these effects do not show up in German; according to Haider, the German analogues of English superiority violations are grammatical. Similarly, Korean, which seems to follow the pattern of Japanese in this respect, does not have superiority like in English; see Watanabe (1992) for a discussion of anti-superiority effects in Japanese.

Due to a further lack of restrictions like the sentential subject constraint (cf. Haider (1983), Grewendorf (1988)), the grammaticality of Shortest Path violations in German can be checked with examples different from the original superiority cases of English. For example, consider the following synonymous sentences, both of which are grammatical:

$$
\begin{aligned}
& \text { a. } \left.\mathrm{Wen}_{1} \text { hat [CP [IP PRO t } \mathrm{t}_{1} \mathrm{zu} \text { betrügen }\right]_{\text {wem }} \text { nicht gefallen? } \\
& \text { Whom has to fool whom not pleased } \\
& \text { 'To fool whom didn't please whom?' }
\end{aligned}
$$

In English, the analogue of (40-a) would constitute a violation of the constraint against extraction from a subject clause and thus could not be used as an example relevant for Shortest Paths. In German, however, the extraction in (40-a) is fine. As can easily be verified, its extraction path is longer than the path of the object in (40-b). Here again, defining RSs in terms of identity of numeration or identity of meaning as in Kitahara (1993) would make the wrong prediction. But identity of LFs might work: recall that Kitahara's explanation of superiority in English, if correct, relies on the assumption that wh-phrases do not move at LF. Consequently, LF-identity puts all superiority cases into different RSs, which is exactly what we want for a language like German.

On the other hand, LF-identity does not make any empirically testable predictions with respect to the data under discussion. Since the analogues of the ungrammatical 
English examples explained by Shortest Paths are grammatical in German, LF-identity is empirically void in this domain; for that matter, we might as well have chosen S-structure identity as the relevant parameter. In order to detect a difference between the two options, it will be necessary to investigate other metrics. Before doing so in the next section, I would like to briefly speculate about the theoretical impact and the descriptive power of the new kind of parameter.

Once we are willing to admit parametrizations of the above sort, the question arises of what possibilities to define RSs there are. If the components used to define RSs in the discussion above can, at least in principle, also play a role in choosing the "correct" parameter, the relevant parameter values concern identity of meaning, LF-identity, Sstructure identity, identity of numeration, and convergence. On the assumption that these values can be set independently, we are faced with a great variety of options. The whole realm of possibilities is illustrated in the following table:

\begin{tabular}{r||l|c|cccc}
\multicolumn{1}{c||}{$411)$} & convergence & same & same & same & same \\
& & & numeration & S-Structure & LF & meaning \\
\hline \hline 1 & cf. Chomsky 1993 & + & + & - & - & - \\
2 & German? & + & - & + & - & - \\
3 & cf. Epstein 1992 & + & - & - & + & - \\
4 & cf. Kitahara 1993, Fox 1994 & + & + & - & - & + \\
\hline $5-6$ & German-like? & + & $(+/-)$ & + & - & + \\
7 & Epstein-like & + & + & - & + & - \\
8 & German-like? & + & + & + & - & - \\
\hline $9-12$ & shortest expression language & $(+/-)$ & - & - & - & $(+/-)$ \\
13 & no movement language & - & + & - & - & - \\
$14-15$ & no LF-movement & - & $(+/-)$ & + & - & - \\
$16-19$ & no overt movement & - & $(+/-)$ & - & + & $(+/-)$ \\
\hline $20-27$ & other combinations ... & $(+/-)$ & $(+/-)$ & + & + & $(+/-)$ \\
$28-29$ & & + & $(+/-)$ & - & + & + \\
$30-31$ & & - & $(+/-)$ & + & - & + \\
32 & & - & + & - & - & +
\end{tabular}

Many combinations of + and - have interesting theoretical properties although the resulting RSs are sometimes too large to characterize any known natural language. This is often the case if convergence is not part of the definition. In general, lack of convergence will neutralize the distinction between strong and weak features, because one would have to compare a convergent derivation (which involves movement in order to be convergent) with a more economical derivation which lacks movement but for this very reason does not converge. The derivation without movement will win; hence, there cannot be movement in such a language (cf. \#13 in table (41)).

Similarly, other combinations of parameters can characterize languages that are unable to make use of either weak or strong features for the purpose of convergence. Assume, e.g., that the relevant criterion is S-structure identity, so that convergence has been dropped from the definition of RSs (cf. \#14 and \#15 in (41)). S-structure identity ensures that movement prior to SPELL-OUT is not blocked by Fewest Steps (cf. below), but LF movement now becomes unmotivated and is ruled out. We thus arrive at a combination that does not seem too implausible to exist in natural languages, in fact one that yields languages that "wear their LF on their sleeves" (Pesetsky (1987, p. 117; 1989, p. 51)). 
On the other hand, it is obvious that these parameter settings overlap with the role played by strong and weak features. For instance, a language without LF movement can alternatively be characterized as one without weak features. In such a language, the economy constraint and the non-existence of certain features do the same job, so that one of them could be dispensed with. Since the feature mechanism is independently motivated in the description of most other types of languages, it appears that parametrizing along the above lines does not square well with the overall design of the minimalist theory. Giving priority to the feature mechanism, as I will do, will then reduce the number of options significantly, allowing us to eliminate a "redundant" parameter by assuming that convergence cannot be parametrized; it is indeed a necessary property shared by all derivations in a RS.

Turning next to "same numeration," it is obvious that certain combinations of parameters do not allow a negative value for this parameter. For example, dropping this criterion as in \#9 to \#12 of (41) would result in languages without paraphrases, i.e. alternate expressions of different complexity (to mention a famous example from Katz \& Fodor (1963, p. 175), Two chairs are in the room would block There are at least two things in the room and each is a chair). In contrast, same numeration seems dispensable if S-structure or LF identity is the relevant condition for defining RSs. Müller \& Sternefeld (1996) have shown that a theory which adopts same numeration in addition makes fewer correct predictions than one that doesn't, arguing that \#3 should be preferred over \#7.

As a general guideline for comparing possible definitions of RSs and for evaluating the resulting theories, methodology prescribes that the strongest theory should be preferred. Against the background of the general framework described in section 1, the strength of a theory can be determined as follows:

(42) a. The more conditions imposed by the definition of a RS, the smaller the RS.

b. The smaller the RS, the weaker its capacity to exclude (ungrammatical) derivations.

c. The weaker the predictions of a theory, the less attractive its corresponding choice of RS.

Thus, the strongest theories are the ones with as few +'s as possible. According to this criterion, the theories \#1 to \#4 are the strongest theories with reasonable predictions. I will refer to these as the four major theories and will abbreviate $\# 1$ to $\# 4$ as $\mathrm{RS}_{N}, \mathrm{RS}_{S}$, $\mathrm{RS}_{L F}$, and $\mathrm{RS}_{M}$, respectively.

Summarizing so far, the result we have arrived at is this: If one is willing to parametrize the definition of RSs, there are only four possibilities that are reasonable a priori. Which is the correct one is still not entirely clear. $\mathrm{RS}_{N}$ seems too strong to be a theory of English, since it leads to difficulties with respect to the counterexamples to superiority in English. $\mathrm{RS}_{S}$ cannot deal with superiority either, but since there are no superiority effects in German or Korean, $\mathrm{RS}_{S}$ might still be an option for these languages. $\mathrm{RS}_{L F}$ allows of two further options concerning the definition of the Shortest Paths metrics and the question of whether or not there is wh-movement at LF. None of these possiblities, however, is consistent with Fox's theory, which requires $\mathrm{RS}_{M}$. As pointed out above, however, this theory is conceptually undesirable and in conflict with data from German and Korean. 
Nonetheless, if correct, $\mathrm{RS}_{M}$ is still the best choice for English, whereas other choices like $\mathrm{RS}_{S}$ or $\mathrm{RS}_{L F}$ might work for other languages.

The only economy constraint discussed so far is Shortest Paths. One might hope, then, to gain additional evidence in favor of or against some of the above proposals by investigating other specific economy conditions; let us see whether or not Fewest Steps will provide us with additional criteria to decide the matter.

\section{Fewest Steps}

The original version of economy, now called Fewest Steps, is based on the following constraint:

(43) Fewest Steps (standard version; cf. Chomsky (1991), Chomsky (1993), Chomsky (1995)):

If two derivations $\mathrm{D}_{1}$ and $\mathrm{D}_{2}$ are in the same $\mathrm{RS}$ and $\mathrm{D}_{1}$ involves fewer operations than $\mathrm{D}_{2}$, then $\mathrm{D}_{1}$ is to be preferred over $\mathrm{D}_{2}$.

The question then arises of what should count as an "operation" in the sense of (43). In the standard version this notion is based on FORM CHAIN operations, such that $\mathrm{D}_{1}$ is to be preferred over $\mathrm{D}_{2}$ if $\mathrm{D}_{1}$ contains fewer FORM CHAIN operations than $\mathrm{D}_{2}$. This is the version of Fewest Steps I will adopt for the remainder of this paper.

I will first discuss a central case of economy that works under all major theories of RSs, pointing out some consequences for LF movement and the role of features in the theory of movement.

Let us begin with a re-examination of one of Epstein's (1992) major arguments for economy. Intuitively, the universal fact that where in constructions like (44) cannot have matrix scope is a clear case for economy:

(44) Who knows where we bought what?

Following Epstein, I will continue to represent the relation between a wh-phrase and its scope as LF-movement. Now, as described by Epstein, matrix scope of where would involve superfluous LF-movement of where to the higher SpecC. The most straightforward way of blocking this is in terms of economy, by comparing the two LFs in (45):

a. $\mathrm{Who}_{i}$ where $_{j}\left[\mathrm{IP}_{i}\right.$ knows what $_{k}$ we bought $\left.\mathrm{t}_{k} \mathrm{t}_{j}\right]$
b. $\mathrm{Who}_{i}\left[\mathrm{IP} \mathrm{t}_{i}\right.$ knows where what $_{k}$ we bought $\left.\mathrm{t}_{k} \mathrm{t}_{j}\right]$

Whereas the generation of (45-a) from (44) involves four applications of FORM CHAIN, the generation of $(45-\mathrm{b})$ requires only three. Note that we can take this line of argument only if we assume $\mathrm{RS}_{N}$ or $\mathrm{RS}_{S}$. The two derivations differ crucially at LF and in meaning. However, there is also a way to deal with this example on the basis of $\mathrm{RS}_{L F}$ or $\mathrm{RS}_{M}$ if we can rule out the ungrammatical reading by showing that there is an alternative, more economical derivation with the same LF or meaning. This happens to be the case since the LF (45-a) can also be generated as shown in (46): 
(46) a. $\mathrm{Who}_{i}\left[\mathrm{IP}_{i} \mathrm{t}_{i}\right.$ knows what $_{k}$ we bought $\mathrm{t}_{k}$ where $\left.{ }_{j}\right]$ ?

b. $\mathrm{Who}_{i}$ where $_{j}\left[\mathrm{IP} \mathrm{t}_{i}\right.$ knows what $_{k}$ we bought $\mathrm{t}_{k} \mathrm{t}_{j}$ ]

Here, the generation of (46-b) requires only three applications of FORM CHAIN; hence, the ungrammatical reading of (44) is also blocked under $\mathrm{RS}_{L F}$ and $\mathrm{RS}_{M}$.

Although the phenomenon as such seems independent of any particular choice of RSs, the above reasoning relies on LF-movement, so that giving up LF movement as discussed above would deprive us of almost all of Epstein's arguments in favor of Fewest Steps. For example, his proof that wh-phrases cannot be topicalized (or adjoined to VP) relies heavily on the assumption that overt movement of the wh-phrase still implies a second movement operation at LF, leading to a result that could be obtained more economically with only one movement operation. And similar considerations apply to all other arguments presented by Epstein. Accordingly, it seems that some economy-relevant relation between the surface positions of $w h$-phrases and their scopal positions is indispensable although we might remain neutral with respect to the question of whether this operation should not be called "movement" or not. One might as well assume that the relevant relation is some sort of indexing that enters into the calculation of Fewest Steps but might not count in the calculation of Shortest Paths. As a way to maintain consistency with lack of LF-movement, one might therefore assume the following:

(47) The relation between a wh-phrase and a remote operator that binds it is an instance of FORM CHAIN.

An operator is remote from a wh-phrase if the two are not located in the same Cprojection at surface structure/LF. This allows us to maintain Epstein's theory without being committed to real movement of wh-phrases at LF.

Let us next look at some conceptual problems of the theory. Recalling our previous decision to adopt the cycle as an independent principle, it is obvious that the ungrammatical derivations considered above violate the cycle at LF; hence, the example chosen by Epstein is ruled out on independent grounds. However, it might be premature to conclude from this that economy is completely redundant with respect to illegal SpecC to SpecC movement. According to Rudin (1988), in Slavic languages like Bulgarian all wh-phrases must move overtly into SpecC, so that the analogue of what must move already overtly into its scope position at S-structure. Hence, LF movement only involves movement of where. This additional movement is correctly blocked by economy, although no violation of the cycle could arise.

Granted that the cycle does not rule out similar cases of superfluous movement, we still may observe another overlap which is more problematic. Recall another principle of minimalism, namely Greed (compare Chomsky (1993, p. 31) and Chomsky (1995, p. 400)):

Greed (simplified version):

$\alpha$ can move into a position $\beta$ only if $\beta$ is in the checking domain of some element that checks a (hitherto) unchecked feature of $\alpha$. 
What Greed expresses is in fact a kind of (derivational) economy principle which can be paraphrased roughly as No movement without appropriate features. One might argue, then, that superfluous wh-movement as discussed in Epstein (1992) must presuppose an appropriate weak feature on the wh-phrase, so that Epstein's argument would be based on the implausible assumption that one and the same item bears two features of the same type, which seems close to a contradiction.

But let us, for the sake of the argument, suppose that this is possible. Then, whether movement is an option or not is almost fully determined by Greed and the presence of features. But in many cases this is not really the result we want. For example, whether a wh-phrase can be topicalized or not would, according to our present assumptions, depend on the presence or absence of a top feature. Nonetheless, topicalization of wh-phrases should be ruled out in principle; i.e., the fact that the embedded topicalizations like (49) in English, or analogous cases like (50-b) and (51-b) in German, are ungrammatical should follow from a general theory of economy whose effects should not be cancelled or overridden by an accidental distribution of features.

*Who believes that what John bought?
a. Fritz sagte [TopP Maria ${ }_{i}$ habe $_{\text {Top }}\left[\right.$ IP $_{i}$ Achim geküsst ]]. Fritz said Maria has $_{\text {subj }}$ Achim kissed
b. *Fritz sagte [TopP wer habe ${ }_{\text {Top }}\left[{ }_{\text {IP }} \mathrm{t}_{i}\right.$ Achim geküsst ]]. Fritz said who NOM $_{\text {has }}$ subj Achim kissed
a. Wer sagte [TopP Maria $_{i} \quad$ habe $_{\text {Top }}\left[\mathrm{IP}\right.$ Achim t ${ }_{i}$ geküsst ]] ? who said Maria $A C C$ has $_{s u b j}$ Achim kissed
b. *Wer sagte [TopP wen $_{i}$ habe $_{\text {Top }}\left[\right.$ IP Achim $t_{i}$ geküsst ]] ? who said whom $_{A C C}$ has $_{\text {subj }}$ Achim kissed

This implies that if we look for alternative derivations that are cheaper in the sense of economy, these must be derivations that use fewer features. In other words, Fewest Steps should prefer derivations with as few features as possible. For this to be feasible we must assume that at least some features that trigger movement cannot be part of the numerations or the structures that constitute RSs. Given that a wh-feature on a wh-phrase is obligatory, and assuming that topicalization features are optional, this means that we have to find a derivation in the same RS that does without the top feature, i.e. without topicalization. Note in passing that such a surface structure will necessarily differ from the structure to be blocked, a fact which immediately rules out $\mathrm{RS}_{S}$ as a possible theory for Fewest Steps.

Granted that optional features do not enter into the calculation of RS, the comparison between structures with and without topicalization is straightforward for (49) but requires some elaboration for the German examples (50) and (51). The main verb sagte may take either a $[+\mathrm{WH}]-\mathrm{CP}$ or a $[-\mathrm{WH}]-\mathrm{CP}$ as a complement. Assume that it subcategorizes for $[+\mathrm{WH}]-\mathrm{CP}$ in $(50-\mathrm{b})$ and for $[-\mathrm{WH}]-\mathrm{CP}$ in (51-b). Now, the S-structures without topicalization are (52-a) and (52-b) respectively:
a. Fritz sagte [CP wer $_{i}\left[\mathrm{IP}_{i}\right.$ Achim geküsst habe ]]. Fritz said who Achim kissed has 
b. Wer sagte [CP daß [IP Achim wen geküsst habe ]] ? who said that Achim who kissed has

However, these structures differ from the topicalized variants in several respects. Due to the lack of embedded topicalization, there is no verb second movement; in (52-b) there is insertion of a complementizer. The question then arises of whether these structures are similar enough to be in the same RS as their topicalized counterparts.

Let us first discuss clausal structure. As has been shown in Müller \& Sternefeld (1993), there is reason to believe that sentence structure in the Germanic languages is uniform in that every $\mathrm{CP}$ contains a Topic-Phrase. Accordingly, the underlying structures of the above sentences are all identical; they differ only in that in (52) there is an empty topic projection, whereas in (50) and (51) the projection of $\mathrm{C}$ is empty. Now, with the structures being identical, we can turn to the more specific considerations of economy, beginning with identity of numeration. Assuming that daß is an "inserted element," the situation parallels the one already discussed with respect to (10), where do-support, like insertion of daß, has to be ignored in the numeration. Moreover, we must, for the sake of the argument, ignore everything that triggers verb second movement. Under these circumstances, $\mathrm{RS}_{N}$ already gives the correct result: In (52-a) S-structure and LF coincide. This is also the LF of (50-b), which is attained by moving the wh-phrase from SpecTop into SpecC and by undoing verb second movement. The LF of (52-b) is (53):

$$
\text { wer }_{j} \operatorname{wen}_{i}\left[\text { IP } \mathrm{t}_{j} \text { sagte [CP [IP Achim } \mathrm{t}_{i}\right. \text { geküsst habe ]]] }
$$

This is also the LF of (51-b). The transition from (51-b) to (53) again requires reconstruction of head movement; moreover, the trace of LF movement must be deleted. The transition from (52-b) to (53) requires deletion of the complementizer daß. We have shown, then, that in these cases identical LFs can be reached without topicalization of wh-phrases. Such topicalization would require an additional step ruled out by economy.

Note that this argument crucially relies on the assumption that there is real LFmovement; without such movement we would have to establish a scope relation, but this would not be sufficient to put the structures to be compared into the same RSs. As noted above, real LF movement is not necessarily inconsistent with the choice of $\mathrm{RS}_{M}$ for English, but rather is so only under the revised Shortest Paths metrics that does not counterbalance the effect of LF movement. On the other hand, this modification cannot work for German, which lacks superiority. It seems, then, that we are trapped in a contradiction.

Moreover, our present assumptions beg the question of why topicalization as such, which is optional, is possible in the first place. Granted that truth conditions are identical the difference between a topicalized and a non-topicalized structure can only be traced back to a difference in the distribution of features, but this is exactly what we cannot allow to enter into the definition of RSs if economy is to able to play a significant role independent of Greed and convergence. For a language like German, there is no problem, since we have chosen $\mathrm{RS}_{L F}$ so that topicalized and non-topicalized structures differ. However, if we assume meaning invariance for topicalization in English, as seems plausible, we are back to our initial problem with $\mathrm{RS}_{M}$ and the role of features in such a theory. 
To summarize, many of Epstein's arguments are valid only under precisely his presuppositions, namely $\mathrm{LF}$ movement and $\mathrm{RS}_{L F}$. On the other hand, we have Fox's arguments in favor of $\mathrm{RS}_{M}$ and against $\mathrm{RS}_{L F}$. Combining these arguments with our account of superiority lead us into conflicting requirements. Besides further conceptual problems with respect to $\mathrm{RS}_{M}$ and Greed, there are additional empirical problems with Fewest Steps that will be discussed in the next section. These data suggest a much simpler theory in terms of derivational rather than transderivational economy, as we will see in the following sections.

\section{From Transderivational to Derivational Constraints}

As shown in Müller \& Sternefeld (1996), wh-phrases can, under certain well-defined circumstances, undergo optional S-structure movement in languages like German, Russian, Korean, Iraqi Arabic, and Ancash Quechua. For example, as discussed by Wahba (1992), wh-movement in Iraqi Arabic may front a wh-phrase, as shown in (54-a), or may not apply, leaving the wh-phrase in situ, as shown in (54-b):

$$
\begin{aligned}
& \text { a. }\left[\mathrm{CP}^{\mathrm{meno}_{i}} \text { Mona raadat }\left[\mathrm{CP}_{\mathrm{i}}^{\prime \prime} \text { tijbir Su'ad }\left[\mathrm{CP}_{i}^{\prime} \text { tisa'ad } \mathrm{t}_{i}\right]\right]\right] \text { ? } \\
& \text { whom }_{\text {dat }} \text { Mona wanted to force Su'ad to help } \\
& \text { b. [CP - Mona raadat [CP - tijbir Su'ad [CP - tisa'ad meno } \left.\left.{ }_{i}\right]\right] \text { ? } \\
& \text { Mona wanted to force Su'ad to help whom dat }
\end{aligned}
$$

In (54-a) wh-movement of meno ('whom') applies in successive-cyclic fashion via two embedded [-wh] SpecC positions of infinitival clauses to the matrix [+wh] SpecC position. In (54-b) overt wh-movement does not take place at all. As discussed with respect to French, one might account for this situation by stipulating a strong checking feature in the highest $\mathrm{C}$ in (54-a) and a weak checking feature (or no checking feature) for (54-b). But now consider (55):

$$
\begin{aligned}
& \text { a. } \left.\left[\mathrm{CP}-\text { Mona raadat }\left[\mathrm{CP}^{\mathrm{meno}} \mathrm{m}_{i} \text { tijbir Su'ad [CP } \mathrm{t}_{i}^{\prime} \text { tisa'ad } \mathrm{t}_{i}\right]\right]\right] \text { ? } \\
& \text { Mona wanted } \text { whom }_{\text {dat }} \text { to force Su'ad to help } \\
& \text { b. }\left[\mathrm{CP}-\text { Mona raadat }\left[\mathrm{CP}-\text { tijbir } \operatorname{Su} \text { 'ad }\left[\mathrm{CP} \operatorname{meno}_{i} \text { tisa'ad } \mathrm{t}_{i}\right]\right]\right] \text { ? } \\
& \text { Mona wanted to force Su'ad } \text { whom }_{\text {dat }} \text { to help }
\end{aligned}
$$

In (55), overt wh-movement stops at an embedded [-wh] SpecC position, and the ultimate landing site in the matrix clause remains empty. These possibilities reconfirm the standard view that wh-phrases move cyclically through full-fledged clausal infinitives with their own SpecC position. As for economy, it is clear that the structures in (55) require two applications of FORM CHAIN, whereas (54) has only one application of FORM CHAIN. Thus, (54) would incorrectly block (55) if their RSs overlap. But which choice of RSs can make them disjunctive?

Beginning with $\mathrm{RS}_{N}$, recall from the discussion of optional movement in French that one might stipulate a difference in the (phonologically empty) element that checks off wh-movement. In order to achieve the required differences in numeration, this element must be strong in the topmost $\mathrm{C}$ position of (54-a) but weak in the same position in 
(54-b). Thus, a theory based on $\mathrm{RS}_{N}$ would not yet block the structures in (54). However, these assumptions cannot account for the sentences in (55). Comparing these with (54-a) reveals that in all cases there is exactly one strong $\mathrm{C}$ in the respective numerations, but the numeration in and of itself does not tell us anything about the position of the strong $\mathrm{C}$ and hence will put the sentences into the same $\mathrm{RS}_{N}$. This result is unintended, and since the sentences all have the same meaning, it also excludes $\mathrm{RS}_{M}$ from being the correct choice for RSs.

$\mathrm{RS}_{S}$ has already been proven to be inconsistent with previous explanations. $\mathrm{RS}_{L F}$ will work only if there is no LF movement. But this cannot work for the data dicussed by Epstein (1992).

Note furthermore that the above data seem to be at odds with Greed. Since partial movement is a subcase of cyclic movement, the more general problem is the justification of single applications of Move- $\alpha$ in cases of S-structural COMP-to-COMP movement. Given that there is no feature to be checked in intermediate SpecC positions, Greed would block Move- $\alpha$. One might therefore conclude instead that Greed constrains the operation FORM CHAIN. This assumption resolves the problem but creates a conflict between derivational and representational concepts: On the one hand, Move- $\alpha$ is a purely local derivational concept, and in the same vein, Greed was intended as a local derivational constraint; on the other hand, the concept of a chain is a representational one, so that FORM CHAIN is - unlike Move- $\alpha$ - a representational, non-local operation.

As a reaction to this problem, Müller (1995) has proposed that Greed should indeed restrict Move- $\alpha$, but at the same time should permit movement without immediate feature checking. Elaborating on, and modifying, an idea of Collins (1994b), Müller suggests that a moved item $\alpha$ can be "fooled" into movement to a certain position if that is a typical checking position for an unchecked feature of $\alpha$. This feature may then be checked immediately, but it may also be checked only after further movement into another typical checking position for $\alpha$ has taken place.

Greed (revised):

A category $\alpha$ can be moved to a position $\beta$ only if $\beta$ is a typical checking position for an unchecked morphological feature of $\alpha$.

For instance, partial wh-movement in Iraqi Arabic would be consistent with economy, assuming no checking operation at S-Structure. Rather, checking is delayed to LF, as one would expect; hence, all derivations in (54) and (55) involve only one checking operation and are equivalent from the point of view of economy. In particular, the above examples are in accord with Müller's (1995) reformulation of Fewest Steps, which dispenses with the operation FORM CHAIN:

Fewest Steps (revised):

If two derivations $\mathrm{D}_{1}$ and $\mathrm{D}_{2}$ are in the same $\mathrm{RS}$ and $\mathrm{D}_{1}$ involves fewer checking operations than $D_{2}$, then $D_{1}$ is to be preferred over $D_{2}$.

Greed and (more indirectly) Fewest Steps presuppose a somewhat extended use of "morphological features," in that each such feature derives its function from being associated with a particular type of movement operation. Following Müller, the features in (58) 
trigger A-movement, wh-movement, scrambling, and topicalization, respectively; these features are in turn associated with appropriate checking positions as listed in (59) - cf. Müller (1995, p. 93):

Morphological Features:

a. obligatory: [Case], [+wh]

b. optional: [scr], [top]

Typical Checking Positions:

a. The typical checking position for [Case] is an A-position.

b. The typical checking position for $[+w h]$ is the minimal residue of $\mathrm{C}$.

c. The typical checking position for [scr] (in German, Korean) is the minimal residue of $\mathrm{V}, \mathrm{AGR}_{O}$, $\mathrm{T}$, or $\mathrm{AGR}_{S}$.

d. The typical checking position for [top] is the minimal residue of the head Top of a topic phrase; cf. Müller \& Sternefeld (1993).

Now it is clear that Müller's idea that Greed plus typical checking positions for Case, top, scr, wh, etc. restrict movement derivationally without implying actual checking of a feature can account for the problem of partial movement under any definition of RSs, as far as Fewest Steps is concerned. As for Shortest Paths, however, it seems that we encounter the same problem as with scrambling, because wh-movement is longer to various degrees. Here again, in situ interpretation of $w$ h-phrases would work, but only at the price of being inconsistent with Epstein's account of economy.

As a first step toward a solution of the problem, observe that Revised Greed operates very similarly to the way in which the Principle of Unambiguous Binding (PUB - cf. Müller \& Sternefeld $(1990,1993))$ restricts movement by reference to types of positions. The PUB states that A-bar movement must be uniform in the following sense: Once A-bar movement to a position of a certain type has occurred, subsequent movement of the same item can choose only the same type of position as a landing site. In other words, if there is some feature that triggers A-bar movement into some type of position, there cannot be any other (unchecked) feature on the same item that would require subsequent movement into another type of position. If this were the case, a variable would receive binding relations from different types of positions, which is precluded by the principle.

For example, the fact that topicalization cannot precede wh-movement follows directly from the PUB, regardless of whether or not we assume movement at LF. If we do, we have improper movement; if we don't, we have still have improper binding from both an abstract wh-operator and the topic position. The principle as such turns out to be neutral with respect to the question of LF-movement.

Given roughly the same classification of positions as in (58), it has been shown in Müller \& Sternefeld (1996) that the PUB can account for all the economy effects described by Epstein (1992). Moreover, a comparison between the derivational PUB and the transderivational theory of fewest checking operations will reveal that the empirical impact of the PUB is stronger than that of Greed and Fewest Steps taken together. Thus, Gereon Müller (p.c.) has pointed out to me that (60) is ruled out as a straightforward violation of Unambiguous Binding but is not ruled out under the present definitions of 
Greed and Fewest Steps.

Super-Raising followed by wh-movement:

${ }^{*} \mathrm{Who}_{1} \mathrm{t}_{1}^{\prime \prime}$ seems [CP $\mathrm{t}_{1}$ that it is likely [IP $\mathrm{t}_{1}$ to win $\left.]\right]$ ?

The wh-phrase bears both a [Case] feature and a [+wh] feature. According to Revised Greed, and due to the presence of the $[+w h]$ feature, movement may first go to the embedded SpecC position. On account of the [Case] feature, it may then go to the matrix SpecI position. Finally, due to the still unchecked $[+w h]$ feature again, it may end up in the matrix SpecC position.

Another case in point is wh-movement at LF from a $[-\mathrm{wh}]$ position as illustrated in (61):

Wh-movement at LF from a [-wh] position:

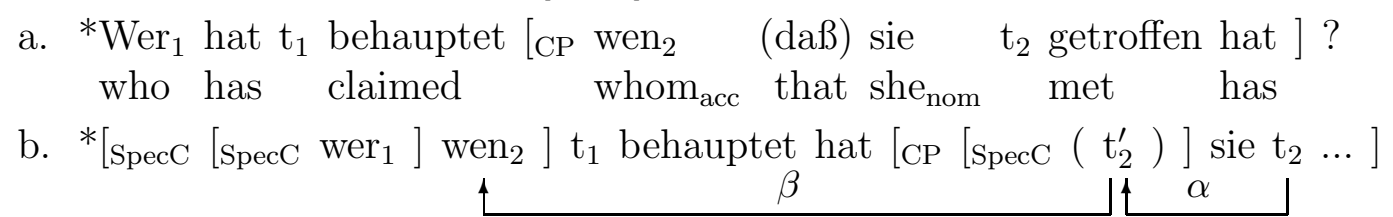

This derivation violates the PUB (given that SpecC substitution and SpecC adjunction positions are different types of positions). However, granted that movement of a whphrase to an intermediate [-wh] SpecC position does not yet involve feature checking (this assumption was necessary in order to permit successive-cyclic wh-movement and partial wh-movement), it is unclear why (61) should be excluded by Greed or Fewest Steps.

Finally, it is also unclear how Fewest Steps can account for parametric variation with respect to $w h$-scrambling. As mentioned above, adjunction of a $w h$-phrase to VP or IP is ungrammatical in English (cf. the discussion in Epstein (1992)), but the very same type of adjunction is grammatical in Korean. In Müller \& Sternefeld (1993) and Müller \& Sternefeld (1996), this difference was accounted for by saying that in a language like Korean, the PUB applies prior to SPELL-OUT and then applies anew after SPELLOUT, which basically means that it restricts FORM CHAIN. In contrast, in languages like English, the principle looks at the entire derivation. Comparing this account with the minimalistic one, it is not clear how any language-specific differences could be built into the transderivational theory. What we want is a systematic account of why wh-phrases are incompatible with other movement features in one type of language but not in another. Parametrization of RSs offers no solution towards that end.

To summarize, I have indicated that a derivational constraint like the PUB can deal with a number of facts that even Collin's transderivational version of Greed cannot accounted for. For a more detailed discussion, I have to refer the reader to Müller \& Sternefeld (1996). Here, I can only emphasize that the need for an alternative explanation arises independently from the choice of RSs; there is no parameter-setting that would automatically solve the problems of a transderivational theory. 


\section{Derivational Accounts of Superiority}

Our concern in the last section was with Fewest Steps alone, hence it remains to deal with Shortest Paths. Having shown that the standard version of Shortest Paths makes wrong predictions in German and Korean (cf. section 3) and that some of its effects are explained by the extension condition (cf. section 4), we could dispense with Shortest Paths if it were not for the superiority effects in English. Let us first explore an alternative way of looking at the phenomenon. Danny Fox (p.c.) has suggested a straightforward reformulation of Chomsky's transderivational economy account of superiority in purely derivational terms. The following condition does the job:

Superiority (2):

A category $\alpha$ with a feature $\mathrm{F}$ can be moved to a position $\beta$ only if there is no category $\gamma$ with an unchecked feature of the same type as $\mathrm{F}$ that is closer to $\beta$.

Observe that (62) faithfully paraphrases Chomsky's original superiority condition, giving the correct results for the normal cases of superiority but still making the wrong prediction for the counterexamples discussed in section 2. This proves that a direct derivational counterpart of the transderivational constraint is possible, but since the transderivational constraint fails, the derivational one does so too.

In order to overcome the problem posed by the anti-superiority cases, let us introduce an additional descriptive device that has already been used in Stechow \& Sternefeld (1988, p. 344ff) for the description of scope marking in German. There it was proposed that certain wh-pronouns like was 'what' in German can be used as scope markers to express wide scope in German. Rather than using long wh-movement (which is barred in many dialects of German), wide scope of a wh-phrase is indicated by a scope marker that is inserted in a distant SpecC, the logically correct scopal position. Overt movement of the "real" wh-phrase goes only to the closest available SpecC position. The scope marker and the real wh-phrases are coindexed (at the relevant levels of representation) if and only if they have the same scope. We use superscripts to express scope-indexing and to describe the syntactic distribution of the scope marker was. See (63) for relevant examples:

a. $\operatorname{Was}^{i}$ glaubst du $\operatorname{wer}_{j}^{i}$ wen $_{k}^{i}$ getroffen hat?

What believe you who whom met has

'Who do you believe has met whom?'

b. Was $^{i}$ glaubst du was $^{i}$ Fritz meint $\operatorname{wer}_{j}^{i}$ gekommen ist?

What believe you what Fritz thinks who come is

'Who do you believe Fritz thinks has come?'

Observe that the scope marker was is deleted at LF and that the indexing device is meant to imply that the coindexed wh-phrases move at LF to the highest SpecC position with the same index as the scope marker (or are left in situ and become bound by an abstract operator in the highest coindexed SpecC).

Let us now look at multiple questions without a morphological scope marker. Once we accept scope coindexation as a legitimate syntactic device, the superiority data seem to be amenable to any treatment that can refer to scope indexing. Suppose we interpret 
scope indices as features of lexical items that enter significantly into numerations. The relevant $w h$-phrases in the problematic anti-superiority cases now have different scope indices; accordingly, they cannot be elements of the same numeration. The relevant data could then be explained even when adopting Chomsky's definition of RSs.

Alternatively, we can build scope indices into our derivational version of superiority:

Superiority (3):

A category $\alpha$ with a feature $\mathrm{F}$ can be moved to a position $\beta$ only if there is no category $\gamma$ with an unchecked feature of the same type and with the same scope index as $\alpha$ that is closer to $\beta$.

In contrast to Superiority (2), (64) can account for the anti-superiority data, but none of the above proposals can account for the lack of Superiority in German. How can we account for this parametric variation?

Perhaps the most straightforward solution is in terms of another well-known derivational constraint that seems to allow for parametric variation, namely the cross-over condition. What goes wrong in superiority violations in English is that a wh-phrase is moved across another wh-phrase with the same scope, and hence the same index:

a. ${ }^{*} \mathrm{Whom}_{2}^{i}$ did John persuade whom ${ }_{1}^{i}\left[\right.$ PRO to visit $\left.\mathrm{t}_{2}\right]$ ?

b. Whom ${ }_{1}^{i}$ did John persuade $t_{1}\left[\right.$ PRO to visit whom $\left._{2}^{i}\right]$ ?

Clearly, the index $i$ must be crossed over in (65-a) but not in (65-b); thus, the assumption of scope co-indexation yields a straightforward explanation by subsuming superiority under an appropriate cross-over condition.

Now, observe that German seems less restrictive with respect to cross-over than English. For example, it has often been claimed in the literature that dialects of German or Korean tolerate weak cross-over violations; see e.g., Lee \& Santorini (1994, p. 261):

$$
\begin{aligned}
& \text { a. daß jeden } \text { jeine }_{i} \text { Kinder } \mathrm{t}_{i} \text { liebhaben. } \\
& \text { that everyone }{ }_{A C C} \text { his }_{N O M} \text { children }_{N O M} \text { dear-have } \\
& \text { 'that everyone is loved by his children.' } \\
& \text { b. nwukwuna-lul } \text { pro }_{i} \text { chinkwu-ta } \mathrm{t}_{i} \text { paypanhayssta }(\mathrm{K}) \text {. } \\
& \text { everyone }_{A C C} \quad \operatorname{pro}_{G E N} \text { friend }_{N O M} \text { betrayed } \\
& \text { 'everyone was betrayed by his friend.' }
\end{aligned}
$$

Although I have some reservations with respect to the full acceptability of the German example, it is easy to construct sentences that are fully grammatical. Thus, consider (67):

$$
\begin{aligned}
& \text { Einen Professor, den alle seine }{ }_{i} \text { Studenten verehren, gibt es } \\
& \text { a professor, who } \text { all }_{N O M} \text { his }_{N O M} \text { students }_{N O M} \text { worship exists EXPL } \\
& \text { hier nicht. } \\
& \text { here not }
\end{aligned}
$$

'There is no professor here who is worshipped by all of his students.'

This example differs from the cases considered by Lee \& Santorini (1994) in that the local binder is not a quantified expression but a relative pronoun. 
Although in general such violations of weak cross-over seem more acceptable than other types (cf. Chomsky (1982, p. 93), Lasnik \& Stowell (1991, p. 698ff), or Postal (1993, fn $1)$ ), it is fairly clear that weak superiority effects are still much weaker in German than in English. In contrast, cases of strong cross-over are ungrammatical in both languages. We thus have the following situation:

(68) a. There is a purely formal (but language-particular) constraint against crossover that is operative in English but does not apply to German.

b. There are independent universal constraints, e.g. the theta-criterion or principle (C) of binding theory as proposed in Chomsky (1981), that explain strong cross-over violations in both languages.

Accordingly, (68-b) takes care of the usual cross-over violations while still permitting for cross over of wh-phrases, which is not ruled out on independent grounds. The latter is still ruled out by (68-a) in English, but is allowed in German, as a consequence of allowing weak cross over in that language.

The existence of independent constraints that take care of strong cross-over has rarely been disputed in the literature. Weak cross-over, on the other hand, seems more problematic. As pointed out to me by Gereon Müller (p. c.), the analogue of (67) is judged grammatical for English as well; cf. Chomsky (1982, p. 93) Freidin (1992, p. 346, fn 25); hence, (68-a) is in need of further elaboration (cf. also Lasnik \& Stowell (1991)). Another elaboration would be called for by the observation that we do find some very weak cross-over effects in cases of long movement, as shown in (69):

(69) ?Wen $_{1}$ sagte seine ${ }_{1}$ Mutter daß Johann $t_{1}$ besuchen soll

Whom said his mother that John visit should

The important observation is again that this effect correlates with a superiority effect with long distance movement:

$$
\begin{aligned}
& \text { ?Wen }_{1} \text { sagte wer daß Johann } t_{i} \text { besuchen soll } \\
& \text { Whom said who that John visit should }
\end{aligned}
$$

Whatever the correct description of the data might be it is obvious that the cross over effects are to be captured in derivational terms; hence, the corresponding superiority effects must also be amenable to a derivational description rather than being captured in transderivational terms.

\section{A Derivational Account of Quantifier Raising}

Let me finally turn to the data examined by Fox. I will show that in this case too a derivational reformulation is readily available.

The key to a derivational treatment of the data lies in the observation that the locality of Fox's constraint implies that looking at a single derivation is already sufficient to tell whether or not it obeys the transderivational economy principle. This is so because QR must always be triggered by a scope dependent item: in contrast to movement, which is 
triggered by a feature, the motivation for $\mathrm{QR}$ is to gain scope, i.e. to make some scope dependent interpretation available. Ideally, then, we have the following generalization (71), which could easily be incorporated into Greed as shown in (72):

(71) No meaning invariant QR.

(72) Supplement to Greed:

A quantifier $\alpha$ may raise to a position $\beta$ only if it gains semantic scope over some $\gamma$, i.e. only if, as a consequence of that operation, some $\gamma$ receives a scope dependent interpretation, which it would not otherwise have.

(73) Representational Version of (72):

For any QR-chain an element must exist that is semantically scope dependent on the head of the chain but is not in the c-command domain of the (lowest) trace of the chain.

However, the story might not be as simple as that. Consider the following example from Fox (1994):

Mary loves every teacher, and some boy does too.

There are at least some speakers of English (including Fox) who find (74) ambiguous. The crucial reading is the one where some boy may be interpreted as scope dependent on every teacher, although QR in the first conjunct would be semantically vacuous. A local condition like (73), which looks only at a single chain, would block QR, thereby leading to a violation of the parallelism constraint. We must, therefore, reformulate the condition in such a way that the link between $\mathrm{QR}$ and scope is more indirect:

Supplement to Greed, revised:

Within any cyclic domain, a quantifier $\alpha$ may raise to a position $\beta$ only if, as a (direct or indirect) result of that operation, there is some $\gamma$ in $\Sigma$, such that $\gamma$ can receive a scope dependent interpretation which it would not otherwise have.

This leaves it open whether $\gamma$ is directly scope dependent on $\alpha$ or whether the scope dependent interpretation is induced by the parallelism constraint. Accordingly, whether or not movement is allowed depends on two conditions: Either QR is triggered by scope, or it is legalized in order to satisfy another constraint of grammar, namely parallelism.

This is a remarkable result. First, it shows that Fox's constraint can be formulated in a purely derivational way. Second, it shows that the original appeal to the cycle is essential and cannot be replaced by any other known condition of grammar.

However, for this theory to work properly, we have to make a crucial assumption, namely, that the two structures to be compared, one before and one after QR, can both be semantically interpreted. In particular, the structure before $\mathrm{QR}$ must receive some semantic interpretation which, in order for QR to be well-formed, crucially differs from the interpretation after QR. This state of affairs requires a particular version of an incremental theory of the syntax-semantics interface: it presupposes that S-structure can, in principle, be interpreted before LF operations like QR apply. In general, then, even wh-terms should be interpretable before movement, which corresponds to the view 
advocated by Pesetsky (1987), Reinhart (1992), and others, namely, that wh-words are interpreted as variables. The theory thus predicts that there is no "type-driven" QR nor is there any "type-driven" wh-movement. This result has of course a great number of further ramifications that lie outside the scope of this investigation.

\section{General Conclusion}

In this paper I have pointed out some difficulties in the theory of RSs. As a solution I proposed that the transderivational principles like Shortest Paths and Fewest Steps should be replaced by derivational constraints like Greed, the cycle, and PUB. Moreover, depending on further assumptions regarding the deletability of traces, some of these conditions can also be stated in a purely representational way; cf. Müller \& Sternefeld (1993). Very much the same holds for the cross-over constraint (which is almost always stated representationally; cf. Chomsky (1981)) and for a number of further derivational constraints that have representational counterparts; cf. Sternefeld (1991).

I conclude that for the applications I am aware of, the transderivational theory is hardly more explanatory than a derivational or perhaps even a representational one. Moreover, since the construction of RSs imposes a heavy computational burden on the overall system, "inducing high-order computational complexity" (Chomsky (1993, p. 33)), it seems to me that the transderivational device, unless otherwise constrained, might surpass the generative capacity of the human computational system. The least one can say is that the theory is not satisfactorily worked out and that the available empirical evidence for specific proposals is poor.

\section{References}

Baker, Carl L. (1970): 'Notes on the Description of English Questions: the Role of an Abstract Question Morpheme', Foundations of Language 6, 197-219.

Besten, Hans den \& Gert Webelhuth (1990): Stranding. In: G. Grewendorf \& W. Sternefeld, eds, Scrambling and Barriers. Benjamins, Amsterdam, pp. 77-92.

Chomsky, Noam (1973): Conditions on Transformations. In: S. Anderson \& P. Kiparsky, eds, A Festschrift for Morris Halle. Academic Press, New York, pp. 232-286.

Chomsky, Noam (1981): Lectures on Government and Binding. Foris, Dordrecht.

Chomsky, Noam (1982): Some Concepts and Consequences of the Theory of Government and Binding. MIT Press, Cambridge, Massachusetts.

Chomsky, Noam (1991): Some Notes on Economy of Derivation and Representation. In: R. Freidin, ed., Principles and Parameters in Generative Grammar. MIT Press, Cambridge, Massachusetts, pp. 417-454.

Chomsky, Noam (1993): A Minimalist Program for Linguistic Theory. In: K. Hale \& S. J. Keyser, eds, The View from Building 20. MIT, Cambridge, Mass., pp. 1-52.

Chomsky, Noam (1995): Bare Phrase Structure. In: G. Webelhuth, ed., Government and Binding Theory and the Minimalist Program. Blackwell, Oxford \& Cambridge, pp. 383-439. 
Collins, Chris (1994a): 'Economy of Derivation and the Generalized Proper Binding Condition', Linguistic Inquiry 25, 45-61.

Collins, Chris (1994b): Merge and Greed. Cornell University.

Emonds, Joseph (1985): A Unified Theory of Syntactic Categories. Foris, Dordrecht.

Epstein, Samuel David (1992): 'Derivational Constraints on A-bar Chain Formation', Linguistic Inquiry 23, 235-259.

Epstein, Samuel David (1993): 'Superiority', Harvard Working Papers in Linguistics 3, 1464.

Fox, Danny (1994): Quantifier Scope in VP Ellipsis. unpublished ms., MIT.

Freidin, Robert (1992): Foundations of Generative Grammar. The MIT Press, Cambridge/Mass.

Grewendorf, Günther (1988): Aspekte der deutschen Syntax. Narr, Tübingen.

Haider, Hubert (1983): 'Connectedness Effects in German', Groninger Arbeiten zur Germanistischen Linguistik 23, 82-119.

Huang, Cheng-Teh James (1982): Logical Relations in Chinese and the Theory of Grammar. PhD thesis, MIT, Cambridge, Massachusetts.

Katz, Jerold J. \& Jerry A. Fodor (1963): 'The Structure of a Semantic Theory', Language 39, 170-210.

Kayne, Richard (1994): The Antisymmetry of Syntax. The MIT Press, Cambridge, Mass.

Kitahara, Hisatsugu (1993): 'Deducing 'Superiority' Effects from the Shortest Chain Requirement', Harvard Working Papers in Linguistics 3, 109-119.

Koster, Jan (1987): Domains and Dynasties. Foris, Dordrecht.

Lasnik, Howard \& Mamoru Saito (1984): 'On the Nature of Proper Government', Linguistic Inquiry 15, 235-289.

Lasnik, Howard \& Mamoru Saito (1992): Move $\alpha$. MIT Press, Cambridge, Massachusetts.

Lasnik, Howard \& Tim Stowell (1991): 'Weakest Crossover', Linguistic Inquiry 22, 687720.

Lee, Young-Suk \& Beatrice Santorini (1994): Towards resolving Webelhuth's paradox: evidence from German and Korean. In: N. Corver \& H. van Riemsdijk, eds, Studies on Scrambling. Mouton/deGruyter, pp. 257-300.

Müller, Gereon (1995): Cyclicity and Economy. Movement Theory in the Minimalist Program. Universität Tübingen. Distributed at LOT Winterschool, Tilburg University.

Müller, Gereon \& Wolfgang Sternefeld (1990): Improper Movement. Universität Konstanz.

Müller, Gereon \& Wolfgang Sternefeld (1993): 'Improper Movement and Unambiguous Binding', Linguistic Inquiry 24, 461-507.

Müller, Gereon \& Wolfgang Sternefeld (1994): Scrambling as A-bar Movement. In: N. Corver \& H. v. Riemsdijk, eds, Studies on Scrambling. Movement and NonMovement Approaches to Free Word-Order Phenomena. Mouton de Gruyter, Berlin, pp. 331-386. 
Müller, Gereon \& Wolfgang Sternefeld (1996): 'A-bar Chain Formation and Economy of Derivation', Linguistic Inquiry 27(3).

Pesetsky, David (1982): Paths and Categories. PhD thesis, MIT, Cambridge, Massachusetts.

Pesetsky, David (1987): Wh-in-Situ: Movement and Unselective Binding. In: E. Reuland \& A. ter Meulen, eds, The Representation of (In)Definiteness. MIT Press, Cambridge, Massachusetts, pp. 98-129.

Pesetsky, David (1989): Language Particular Processes and the Earliness Principle. unpublished ms.

Postal, Paul (1993): 'Remarks on Weak Crossover Effects', Linguistic Inquiry 24, 359-556.

Reinhart, Tanya (1992): Wh-in-situ: An Apparent Paradox. In: P. Dekker \& M. Stokhof, eds, Proceedings of the Eighth Amsterdam Colloquium. ILLC, University of Amsterdam.

Reinhart, Tanya (1994): Wh-in-situ in the Framework of the Minimalist Program. OTS Working Papers, University of Utrecht.

Stechow, Arnim von \& Wolfgang Sternefeld (1988): Bausteine syntaktischen Wissens. Westdeutscher Verlag, Opladen.

Sternefeld, Wolfgang (1991): Chain Formation, Reanalysis, and the Economy of Levels. In: H. Haider \& K. Netter, eds, Derivation and Representation in the Theory of Grammar. Kluwer, Dordrecht, pp. 75-143.

Thiersch, Craig (1978): Topics in German Syntax. PhD thesis, MIT, Cambridge, Massachusetts.

Thiersch, Craig (1982): 'A Note on Scrambling and the Existence of VP', Wiener Linguistische Gazette 27/28.

Wahba, Wafaa Abdel-Faheem Batran (1992): LF Movement in Iraqi Arabic. In: C.T. J. Huang \& R. May, eds, Logical Structure and Linguistic Structure. Kluwer, Dordrecht, pp. 253-276.

Watanabe, Akira (1992): 'Subjacency and S-Structure movement of Wh-in-situ', Journal of East Asian Linguistics 1, 255-291. 